\title{
INFLUENCE OF CEREBRAL LATERALIZATION ON SHOOTING ACCURACY PERFORMANCE OF FIELD HOCKEY PLAYERS ${ }^{i}$
}

\author{
Mustafa Çilkizii, \\ Mustafa Özdal \\ Gaziantep University, \\ Faculty of Sport Science, Physical Education and Sport Science, \\ Gaziantep, Turkey
}

\begin{abstract}
:
The aim of this study is to examine the effect of cerebral lateralization on drag-flick and shot performance in hockey. For this purpose, 35 elite hockey players participated in the study as subjects. After the lateralization test was applied, the subjects were divided into three groups as dominant right hand, dominant left hand and using both hands, and then shot and drag flick tests were applied to the subjects to determine the effect of lateralization on hockey skills between the groups. The obtained data were analyzed in SPSS 22.0 program. After testing for normality and homogeneity, one-way analysis of variance and LSD correction were performed for multiple groups. When the results were examined, it was determined that hand preference had a significant effect on shooting performance and drag flick performance in favor of right and left hand dominant $(p<0.05)$. As a result, it can be said that the effects of laterization are in favor of the dominant hand in hockey players regardless of whether they are right or left, and individuals using both hands perform negatively in hitting advantageous points.
\end{abstract}

Keywords: hockey, lateralization, drag-flick, shot, hand preference

\section{Introduction}

The anatomical, behavioral or physiological difference between the two brain hemispheres is expressed as brain asymmetry or cerebral palsy. The more developed, more active and larger hemisphere is dominant in its performance. The asymmetry of brain function and its evolutionary origins is an important issue in modern neuroscience (1). He argues that the fact that one hemisphere is structurally different from the other hemisphere or that it performs different tasks from the other means that the brain is asymmetrical. An example of this is that the left hemisphere of the brain controls the

\footnotetext{
i This study was produced from Mustafa Çilkız's master's thesis.

ii Correspondence: email hockeymustafa@hotmail.com
} 
language and speech functions of the human, while the right hemisphere, on the contrary, is related to spatial and emotional functions (2). When we consider the drag-flick and shooting performances in hockey, if we do not look at the dominant hand, it is concluded that cerebral lateralization has an effect on the shooting direction in the performance shown, since the stick grip is the same for all players. When we look at it in this direction, regardless of which hand the players will prefer, considering that the left hand is active in the sport of hockey and has a balancing feature in the right hand, it is believed that the hand preference used by the hockey players during their routine lives also has an important effect on their performance in this sport. In our study, which was carried out within the framework of this subject, which was emphasized as important, it was aimed to investigate the effect on hockey sports techniques for the cerebral lateralization status of the players under the name of hockey sport.

\section{Method}

35 elite hockey players participated in the study. The mean age of the subjects was $14.8 \pm$ 0.47 years, and the mean age of sports was $4.34 \pm 1.81$ years. Our study was designed according to ex post facto research design. Shot and drag flick performance were evaluated as dependent variables independent of manipulation, by considering lateralization as an independent variable that was not manipulated. After the lateralization test was applied, the subjects were divided into three groups as right hand, left hand and both hands, and then shot and drag flick tests were applied to the subjects to determine the effect of lateralization on hockey skills between the groups.

\subsection{Lateralization test}

Edinburgh Inventory Oldfield Questionnaire was applied to individuals in order to determine their hand preference. According to the Geschwind score (11) regarding the frequency of the hand used in each task, all values from 0 to +100 (who marked all questions as right-handed) and from 0 to -100 (who marked all questions as left-handed) were determined. A negative score is evaluated in favor of left-handedness, and a positive score is evaluated in favor of right-handedness. A score below -40 was determined as dominant left-handedness, between $-40 /+40$ as using both hands, and above +40 as dominant right-handedness $(3,4)$.

\subsection{Drag flick test}

Before the test, the subjects were given the right to make a sighting shot. Five sighting shots are allowed. From the dashed line 9 meters in front of the center of the goal line, each subject was asked to shoot twenty shots using the drag flick shot technique towards the hockey goal. Each shot on target, two flags denoting the boundaries of the designated scoring areas were placed on the goal line, 40 centimeters from both posts. If the ball entered the goal between the goalpost and the flag, the participant received two points. If the ball entered the goal between the two flags, the participant received one point. No 
points are awarded if the ball did not enter the goal or if it went beyond the goalposts from any point. Thus, each participant was given points out of a maximum of forty points. The subjects applied the drag flick smash technique, one of the basic hockey techniques, after warming up (5).

\subsection{Hit shot test}

Before the test, the subjects were given the right to make a sighting shot. Five sighting shots are allowed. From the dashed line, which is 9 meters in front of the center of the goal line, each subject was asked to shoot twenty shots towards the hockey goal using the hit shot technique. Each shot on target, two flags denoting the boundaries of the designated scoring areas were placed on the goal line, 40 centimeters from both posts. If the ball entered the goal between the goalpost and the flag, the participant received two points. If the ball entered the goal between the two flags, the participant received one point. No points are awarded if the ball did not enter the goal or if it went beyond the goalposts from any point. Thus, each participant was given points out of a maximum of forty points. The subjects applied the hit hit shot technique, one of the basic hockey techniques, after warming up (5).

\subsection{Statistical method}

SPSS 22.0 program was used for statistical operations. After testing for normality and homogeneity (the kurtosis and skewness of the data that did not show normal distribution were evaluated and those in the $+/-2.00$ score range were assumed to have normal distribution), t-test for independent groups for the analysis of the difference between paired groups, one-way analysis of variance for the analysis of the difference between multiple groups, and LSD post hoc correction test was applied. Values were presented as mean and standard deviation and were analyzed at the 0.05 significance level.

\section{Results}

Table 1: Comparison of hit shooting performance of subjects according to hand preference

\begin{tabular}{|l|c|c|c|c|c|}
\hline & $\mathbf{N}$ & Mean & Std. Dev. & p & Diff. \\
\cline { 1 - 4 } 1. Dominant right & 22 & 39.1364 & 1.67034 & \multirow{2}{*}{0.004} & \multirow{2}{*}{$1-2$} \\
\cline { 1 - 4 } 2. Ambidextrous & 6 & 35.1667 & 4.66548 & \\
\cline { 1 - 4 } 3. Dominant left & 7 & 39.0000 & 1.91485 & & \\
\hline
\end{tabular}

The comparison of shooting performance of the subjects according to hand preference is presented in Table 1. According to the results of the one-way analysis of variance, a significant difference was found between the groups $(\mathrm{p}<0.05)$. According to the results of the LSD correction test, which was conducted to determine between which groups the significant difference there was a significant difference between the dominant righthanded and ambidextrous, and the dominant left-handed and ambidextrous in favor of 
the dominant-handed $(\mathrm{p}<0.05)$. There was no significant difference between dominant right and left handed users ( $\mathrm{p}>0.05)$.

Table 2: Comparison of drag flick performance of subjects according to hand preference

\begin{tabular}{|l|c|c|c|c|c|}
\hline & $\mathbf{N}$ & Mean & Std. Dev. & p & Diff. \\
\hline 1. Dominant right & 22 & 38.4091 & 1.81683 & & \multirow{2}{*}{0.001} \\
\cline { 1 - 4 } 2. Ambidextrous & 6 & 34.0000 & 5.51362 & \\
\cline { 1 - 4 } 3. Dominant left & 7 & 40.0000 & .00000 & & \\
\hline
\end{tabular}

The comparison of drag flick performance of the subjects according to hand preference is presented in Table 2. According to the results of the one-way analysis of variance, a significant difference was found between the groups $(\mathrm{p}<0.05)$. According to the results of the LSD correction test, which was conducted to determine between which groups the significant difference was, there was a significant difference between the dominant righthanded and ambidextrous, and the dominant left-handed and ambidextrous in favor of the dominant-handed $(p<0.05)$. There was no significant difference between dominant right and left handed users $(\mathrm{p}>0.05)$.

\section{Discussion}

When the results obtained were examined, it was seen that the variables of being a lefthanded individual in the family and sports age did not have an effect on the dependent variables. However, hand preference was found to be effective on all dependent variables, including hockey smash and drag flick performance.

Lateralization emerged by examining the behavioral effects of left or right-side preference. The importance of lateralization is known due to rapid interactions in the application of sports branches and it is thought that there are left-handed advantages (6, 7). In a study conducted among cricketers, it was determined that hand preference provides a strategic advantage among both shooters and shooters, especially for lefthanded ones $(8,9,10)$. Similar hand preference advantages were found in baseball (11), tennis $(12)$, boxing $(13,14)$, and fencing $(15,16)$. The advantages of hand preference in sports are based on the ability to predict what opponents will do based on recognizing postural or visual cues related to typical playing patterns $(17,18)$.

Because of the speed of movement in many sports, elite athletes have had to develop very specific predictive skills that allow them to predict the movements of their opponents with reasonable accuracy (17). In the highest sporting competitive conditions, there is little time to react with visual information obtained after the opponent's application (ie after the opponent throws or hits the ball) (19). In this situation, elite athletes have learned to rely on their opponents' visual cues (e.g. arm and wrist position) to predict the upcoming situation and make necessary adjustments in response to this prediction (20). 
When faced with an unusual situation (ie, facing a left-handed opponent), the right-handed athlete's predictions are based on the obtained decision-making heuristics, and as a result, the right-handed athlete's performance decreases (11). The lack of perceptual familiarity with the game techniques and tactical strategies of left-handed opponents causes the athlete to react more slowly due to the deterioration in perceptionaction matching in the athlete (10). Apart from this perceptual advantage or disadvantages of hand preference, studies in the literature have largely shown that lefthanded users have larger right hemispheres and thus exhibit improved motor and spatial functionality abilities $(21,22)$, and shorter reaction latency times $(23,24,25,26)$ hypothesis.

However, Williams and Ericsson (2005) stated that such a separation based on hand preference is unlikely to reflect real performance in sports (27). In our study, it was determined that individuals who use their right and left hands dominantly both achieved higher scores in hockey shot and drag flick performance compared to individuals using both hands, and they were able to hit the ball accurately in more advantageous areas of the goal. In the light of this information, it has been seen that right and left dominance is not effective despite the stability in the use of the hockey stick, but the situation is in favor of the individuals with the dominant hand compared to the individuals who can use both hands. Studies on shooting performance in the literature have also revealed that there is a difference in the direction of the dominant hand (28).

\section{Conclusion}

As a result, it can be said that the effects of laterization are in favor of the dominant hand in hockey players regardless of whether they are right or left, and individuals using both hands perform negatively in hitting advantageous points.

\section{Conflict of interest statement}

There are no potential conflicts of interest on this article.

\section{About the Authors}

Mr. Çilkız has Master of Science degree in sport science research field. Dr. Özdal is Associate Professor Doctor at Gaziantep University, Turkey.

\section{References}

1. Geschwind N, Behan P. Left-handedness: Association with immune disease, migraine, and developmental learning disorder. Proceedings of the National Academy of Sciences. 1982;79(16):5097-100.

2. Bisazza A, Rogers LJ, G Vallortigara. The Origins of Cerebral Asymmetry in Fishes, Amphibians and Reptiles, 1998; 22(3): 411-426. 
3. Menteşe B. Sağlıklı erişkinlerde seks steroid hormon düzeylerinin sinir ileti hızı, reaksiyon zamanı, kognitif fonksiyonlar ve serebral lateralizasyon üzerine etkisi. Manisa Celal Bayar Üniversitesi, Doktora Tezi, 2019 (Danışman Prof.Dr. Necip Kutlu).

4. Geschwind N, Behan P Left-handedness: association with immune disease, migraine, and developmental learning disorder. Proceedings of the National Academy of Sciences, 1982; 79(16):5097-5100.

5. Smith D, Holmes PS, Whitmore L, Collins D, Devonport T, Effect of Theoreticallybased Imagery Scripts on Field Hockey Performance Journal of Sport Behavior, 2001;24(4):408-19

6. Gilbert AN, Wysocki CJ. Hand preference and age in the United States. Neuropsychologia. 1992;30(7):601-8.

7. Grouios G. Motoric dominance and sporting excellence: Training versus heredity. Perceptual and motor skills. 2004;98(1):53-66.

8. Brooks R, Bussiere LF, Jennions MD, Hunt J. Sinister strategies succeed at the cricket World Cup. Proceedings of the Royal Society of London. Series B: Biological Sciences. 2004;271(suppl_3):S64-6.

9. Edwards S, Beaton A. Howzat?! Why is there an over-representation of lefthanded bowlers in professional cricket in the UK?. Laterality. 1996;1(1):45-50.

10. Wood CJ, Aggleton JP. Handedness in 'fast ball' sports: Do lefthanders have an innate advantage?. British journal of psychology. 1989;80(2):227-40.

11. Goldstein SR, Young CA. " Evolutionary" stable strategy of handedness in major league baseball. Journal of Comparative Psychology. 1996;110(2):164.

12. Holtzen DW. Handedness and professional tennis. International Journal of neuroscience. 2000;105(1-4):101-19.

13. Gursoy R. Effects of left-or right-hand preference on the success of boxers in Turkey. British Journal of Sports Medicine. 2009;43(2):142-4.

14. Raymond M, Pontier D, Dufour AB, Møller AP. Frequency-dependent maintenance of left handedness in humans. Proceedings of the Royal Society of London. Series B: Biological Sciences. 1996;263(1377):1627-33.

15. Harris LJ. In fencing, what gives left-handers the edge? Views from the present and the distant past. Laterality. 2010;15(1-2):15-55.

16. Roi GS, Bianchedi D. The science of fencing. Sports medicine. 2008;38(6):465-81.

17. Abernethy B, Russell DG. Advance cue utilisation by skilled cricket batsmen. Australian Journal of Science and Medicine in sport. 1984;16(2):2-10.

18. Grouios G, Tsorbatzoudis H, Alexandris K, Barkoukis V. Do left-handed competitors have an innate superiority in sports?. Perceptual and motor skills. 2000;90(3_suppl):1273-82.

19. Tresilian JR. Perceptual and cognitive processes in time-to-contact estimation: Analysis of prediction-motion and relative judgment tasks. Perception \& Psychophysics. 1995;57(2):231-45. 
20. Panchuk D, Vickers JN. Gaze behaviors of goaltenders under spatial-temporal constraints. Human movement science. 2006;25(6):733-52.

21. Galaburda AM, LeMay M, Kemper TL, Geschwind N. Right-left asymmetrics in the brain. Science. 1978;199(4331):852-6.

22. Mikheev M, Mohr C, Afanasiev S, Landis T, Thut G. Motor control and cerebral hemispheric specialization in highly qualified judo wrestlers. Neuropsychologia. 2002;40(8):1209-19.

23. Taddei F, Viggiano MP, Mecacci L. Pattern reversal visual evoked potentials in fencers. International journal of psychophysiology. 1991;11(3):257-60.

24. Annett M, Kilshaw D. Right-and left-hand skill II: Estimating the parameters of the distribution of L-R differences in males and females. British Journal of Psychology. 1983;74(2):269-83.

25. Bisiacchi PS, Ripoll H, Stein J, Simonet P, Azemar G. Left-handedness in fencers: an attentional advantage?. Perceptual and motor skills. 1985;61(2):507-13.

26. Cherbuin N, Brinkman C. Hemispheric interactions are different in left-handed individuals. Neuropsychology. 200620(6):700.

27. Williams AM, Ericsson KA. Perceptual-cognitive expertise in sport: Some considerations when applying the expert performance approach. Human movement science. 2005;24(3):283-307.

28. Puterman J, Schorer J, Baker J. Shooting side orientation and elite performance in ice hockey. Journal of Exercise, Movement, and Sport (SCAPPS refereed abstracts repository). 2010;42(1):157-. 

copy, distribute, transmit or adapt the article content, providing a proper, prominent and unambiguous attribution to the authors in a manner that makes clear that the materials are being reused under permission of a Creative Commons License. Views, opinions and conclusions expressed in this research article are views, opinions and conclusions of the author(s). Open Access Publishing Group and European Journal of Physical Education and Sport Science shall not be responsible or answerable for any loss, damage or liability caused in relation to/arising out of conflict of interests, copyright violations and inappropriate or inaccurate use of any kind content related or integrated on the research work. All the published works are meeting the Open Access Publishing requirements and can be freely accessed, shared, modified, distributed and used in educational, commercial and non-commercial purposes under a Creative Commons attribution 4.0 International License (CC BY 4.0). 